\title{
Identifikasi Terumbu Karang Genus Favites dengan Menggunakan Metode Reef Identification Knowhow Application-Reconstructed by 3D Imagery (RIKA-R3DI)
}

\section{Identification Genus Favites Corals by Using the Reef Identification Knowhow Application-Reconstructed by $3 D$ Imagery (RIKA-R3DI) Method}

\author{
Rika Kurniawan ${ }^{1 *}$, Dino Adrian², Awaludin Awaludin ${ }^{3}$ \\ ${ }^{123}$ Fakultas Ilmu Kelautan dan Perikanan, Universitas Raja Ali Haji, Provinsi Kepulauan Riau, \\ Indonesia \\ *Korespondensi: rikakurniawan@umrah.ac.id
}

\begin{abstract}
Absrtak
Penggunaaan metode dalam penelitian terumbu karang hingga saat ini sangat banyak digunakan, tergantung tujuan dari seorang peneliti. Metode Reef Identification Knowhow Application-Reconstructed by $3 D$ Imagery (RIKA-R3DI) merupakan hasil pengembangan serta modifikasi dari metode Underwater Photo Transect (UPT). Cara kerja metode ini mengidentifikasi jenis karang dengan menggunakan gambar 3 dimensi (3D), sebelumnya sampel yang merupakan video jenis karang diperoleh dilapangan dengan peralatan selam dan video bawah air. Kemudian video sampel diolah menjadi gambar 3D serta diidentifikasi didarat. Sebelumnya metoda ini digunakan pada karang Genus Acropora dan Favia. Namun saat ini peneliti menggunakan metode RIKA-R3DI dalam mengidentifikasi karang Genus Favites, dengan tujuan apakah metode ini dapat digunakan dalam mengidentifikasi karang Genus Favites. Sampel diambil pada perairan pulau Mapur Provinsi Kepulauan Riau. Hasil dari penelitian menunjukan bahwa metode ini sangat efektif dan berhasil dalam mengidentifikasi karang Genus Favites sampai ke spesies. Hasil uji dan identifikasi sampel, yang telah dijadikan gambar 3D menghasilkan karang Favites abdita.
\end{abstract}

Katakunci: Metode Identifikasi, Metode RIKA-R3DI, Gambar 3D, Favites

\begin{abstract}
The use of methods in coral reef research to date has been very widely used, depending on the goals of a researcher. The Reef Identification Knowhow Application-Reconstructed by 3D Imagery (RIKA-R3DI) method is the result of the development and modification of the Underwater Photo Transect (UPT) method. The way this method works is to identify coral types using $3 D$ images, previously samples that were videos of coral types were obtained in the field with underwater equipment and video equipment. Then the sample video is processed into $3 D$ images and identified on land. Previously this method was used on corals of the Genus Acropora and Favia. But now researchers use the RIKA-R3DI method in identifying corals of the Genus Favites, with the aim of whether this method can be used in identifying corals of the Genus Favites. Samples were taken in the waters of the island of Mapur, Kepulauanriau Province. The results of this study indicate that this method is very effective and successful in identifying coral genus Favites to species. Test results and sample identification, which have been used as 3D images, produce Favites abdita corals.
\end{abstract}

Keywords: Method Identification, Method RIKA-R3DI, 3D Imagery, Favites

\section{PENDAHULUAN}

Indonesia sebagai negara maritim memiliki potensi kelautan yang sangat besar, panjang garis pantai terpanjang kedua di dunia $95.000 \mathrm{~km}$ dan luas laut sekitar 5,8 juta (Lasabuda, 2013; Susanti, 2018). Memiliki Biodiversity yang tinggi terutama ekosistem terumbu karang, 
diperkirakan terdapat lebih dari 80 genera dan 450 spesies terumbu karang di wilayah Indonesia (Suharsono 2008). Pemanfaatan sumberdaya terumbu karang dengan konsep ekowisata merupakan bentuk pemanfaatan yang berkelanjutan (Kurniawan et al, 2016)

Faktor utama yang mempengaruhi pertumbuhan karang adalah intensitas cahaya, oksigen, suhu dan kecerahan air (Giyanto et al. 2017). Menurut Lauretta et al. (2012), Ekosistem di bumi yang paling produktif dan paling kaya dari keanekaragaman hayati adalah ekosistem terumbu karang dan mendapat berbagai ancaman yang semakin hebat, termasuk penangkapan berlebihan, pembangunan pesisir, limpasan dari pertanian, dan pelayaran.

Metode survei yang digunakan dalam mengkaji terumbu karang sangat beragam seperti, metode Manta Tow (Achmad 2013; Restu 2011; Prasetia et al. 2015; Sukmara et al. 2001), metode Line Intercept Transect (LIT) (Saptarini et al. 2016; Rudi 2005; Thamrin et al. 2013; Sarbini et al. 2016, metode Point Intercept Transect (PIT) (Manuputty et al. 2009; Hil et al. 2004), metode Belt Transect (Hermanto 2013; Subhan et al. 2011; Fastawa 2016) dan metode Transek Kuadrat (Mustamu et al. 2014). Metode-metode berikut merupakan yang sering digunakan dalam mengidentifikasi maupun mengetahui bagaimana kondisi terumbu karang di suatu wilayah.

Pengembangan metode baru dalam penelitian terumbu karang makin beragam, hal ini demi mempermudah seorang peneliti. Salah satu metode yang diterapkan saat ini adalah metode Under Water Photo Transect (UPT) (Giyanto et al. 2014; Ilyas et al. 2017) yang memanfaatkan sebuah software Coral Point Count with Excel extensions (CPCe) untuk mengolah data (Kohler et al. 2006; Tabugo et al. 2016). Prinsip metode ini adalah data diambil secara langsung di lapangan (laut) dengan cara diFotokan, setelah itu diolah serta diidentifikasi di darat. Dengan tujuan agar sampel dapat lebih terkontrol. Perbedaan metode ini dengan metode sebelumnya terletak pada cara pengambilan dan pengolahan sampel. Metode sebelumnya sampel masih diolah dan diidentifikasi dilapangan.

Metode Reef Identification Knowhow Application-Reconstructed by $3 D$ Imagery (RIKA-R3DI) digunakan dalam mengidentifikasi genus Acroporidae dan Favidae (Kurniawan et al. 2019). Dalam penelitian ini, peneliti menggunakan metode RIKA-R3DI untuk mengidentifikasi karang Genus Favites. Metode RIKA-R3DI merupakan hasil modifikasi dari metode UPT (Giyanto et al. 2014; Ilyas et al. 2017). 
Peneliti menggunakan sebuah metode baru untuk mempermudah peneliti karang yang tidak memiliki keahlian secara langsung dalam mengidentifikasi terumbu karang di dalam laut, sehingga nantinya peneliti newbie dapat mengolah data dan mengidentifikasi terumbu karang di darat tanpa harus mengidentifikasi secara langsung di lapangan. Sama halnya seperti metode UPT, salah satu kelebihan dalam menggunakan metode ini adalah mendapatkan data yang lebih terkontrol dan bisa dicek kembali kebenarannya dibandingkan metode-metode sebelumnya. Adapun tujuan dari penelitian untuk mengetahui apakah metode ini dapat digunakan dalam mengidentikasi genus Favites dan mengetahui tingkat efektifitas penggunaan metode ini dalam mengidentifikasi genus Favites.

\section{METODOLOGI PENELITIAN}

Metode yang digunakan pada penelitian ini adalah metode survei yang dilakukan dengan pengamatan, pengukuran dan pengambilan sampel langsung di lapangan kemudian dilanjutkan dengan mengidentifikasi sampel menggunakan laptop. Analisa yang digunakan dalam mengidentifikasi karang sampel adalah metode Reef Identification Knowhow Application-Reconstructed by 3D Imagery (RIKA-R3DI) (Kurniawan et al. 2019). Sampel diambil pada perairan pulau Mapur Provinsi Kepulauan Riau. Durasi sampel video yang diambil \pm 2 menit dengan syarat semua sisi terumbu karang diambil secara menyeluruh.

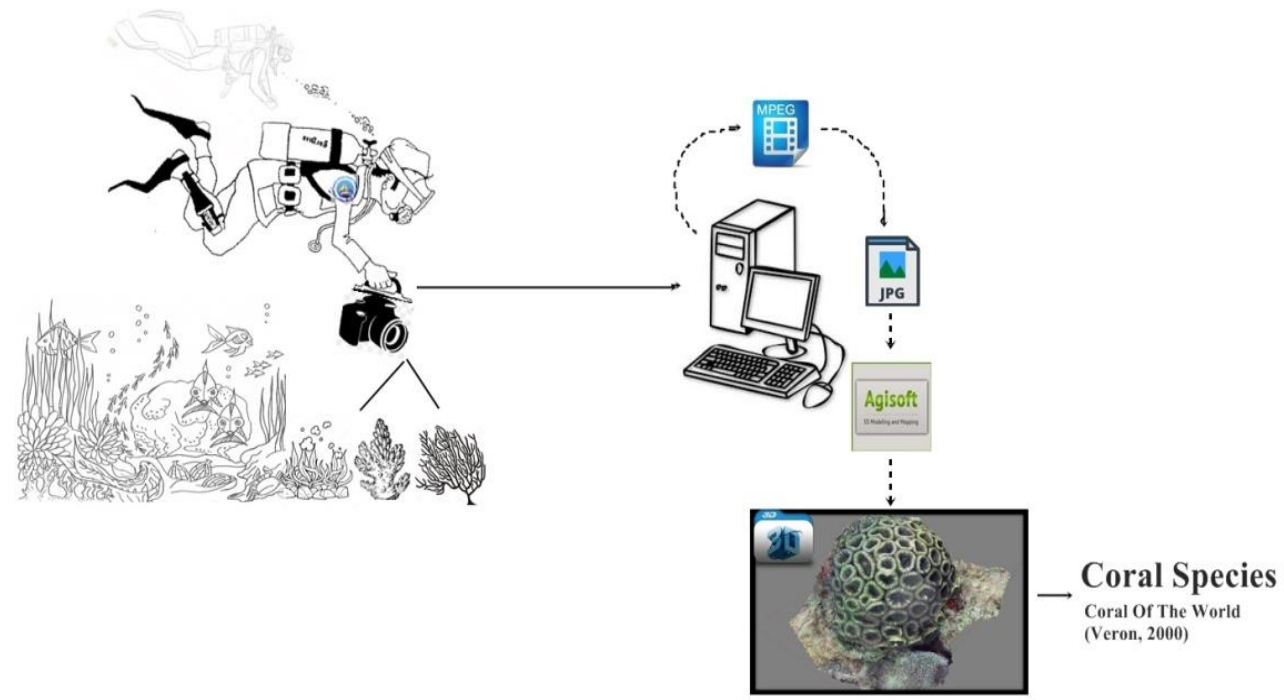

Gambar 1. Ilustrasi Metode RIKA-R3DI (Kurniawan et al. 2019) 
Cara kerja metode ini mengidentifikasi jenis karang dengan menggunakan gambar 3 (tiga) dimensi (3D), sebelumnya sampel yang merupakan video jenis karang diperoleh dilapangan dengan peralatan selam dan video bawah air. Kemudian video sampel diolah menjadi gambar 3D serta diidentifikasi didarat. Sebelumnya metoda ini digunakan pada karang Genus Acropora dan Favia. Namun pada penelitian ini, peneliti menggunakan metode RIKA-R3DI dalam mengidentifikasi karang Genus Favites, dengan tujuan apakah metode ini dapat digunakan dalam mengidentifikasi karang Genus Favites.

\section{HASIL DAN PEMBAHASAN}

Dari hasil survei yang telah dilakukan di Perairan Pulau Mapur Provinsi Kepulauanriau, peneliti mengambil 1 sampel dari Genus Favites yang akan diidentifikasi. Sampel tersebut dianalisis melalui bentuk-bentuk morfologinya supaya mempermudah peneliti dalam mengidentifikasi nama spesies sampel tersebut.

Sampel diambil dan ditentukan langsung oleh peneliti sesuai tujuan penelitian yang akan dilakukan. Sampel yang telah ditemukan kemudian diambil menggunakan kamera bawah air dan direkam kesemua sisi objek minimal selama \pm 2 menit. Proses pengambilan sampel diikuti dengan pengukuran koralit secara langsung dilapangan menggunakan penggaris atau jangka sorong.

\section{Tahapan Pengolahan Sampel}

Tahapan-tahapan yang dilakukan dalam mengolah sampel dari video hingga menjadi ke dalam bentuk tampilan 3D adalah sebagai berikut:

A. Sampel berupa video tersebut di olah menggunakan video converter untuk jadikan kedalam bentuk JPEG sebanyak 75 foto. Pada proses penelitian ini, peneliti memecah video menjadi 75 foto dikarenakan semakin banyak foto yang dipecah maka akan semakin bagus hasil tampilan tiga dimensi (3D) pada tahap berikutnya.

B. Setelah proses pemisahan selesai, foto-foto tersebut dibersihkan menggunakan software Photoshop.

C. Setelah proses pembersihan warna pada software Photosop selesai, selanjutnya sampel yang berupa 75 foto tersebut diolah kembali menggunakan software Agisoft Photoscan. 


\section{Tahapan Dalam Mengidentifikasi Sampel}

Pada tahap identifikasi tentunya perlu untuk mengetahui kunci dan ciri-ciri dalam mengidentifikasi terumbu karang seperti ukuran koralit, bentuk koralit, dan warna dari karang tersebut. Kunci dan ciri-ciri tersebut menjadi tahapan-tahapan yang harus dipenuhi agar spesies yang akan diidentifikasi sesuai dengan sampel yang ditemukan. Berikut ini merupakan tahapan-tahapan yang dilakukan dalam mengidentifikasi sampel dengan panduan buku Coral Finder :

A. Tahap awal yang dilakukan dalam mengidentifikasi sampel adalah dengan memperhatikan bentuk-bentuk morfologi dari terumbu karang itu sendiri. Ukuran koralit yang diukur langsung dilapangan menjadi kunci awal dalam tahap identifikasi genus terumbu karang. Setelah menentukan besar koralit karang yang diidentifikasi maka akan langsung diarahkan pada halaman dimana terdapat jenis-jenis karang yang memiliki besar koralit yang diukur sebelumnya dalam buku Coral Finder.

B. Setelah merujuk kehalaman yang sudah diarahkan dan ukuran koralit dari terumbu karang tersebut telah diketahui, selanjutnya adalah menganalisa bentuk koralit dan warna dari objek untuk mempermudah kita dalam mengidentifikasi nama genus terumbu karang tersebut karena bentuk koralit pada setiap genus karang akan berbeda-beda seperti bentuk koralit yang rapat ataupun terpisah, sehingga penting untuk mengetahui bentuk koralit pada objek tersebut dalam tahap identifikasi.

C. Setelah ukuran koralit, bentuk koralit dan warna terumbu karang sudah diketahui, tahapan selanjutnya adalah mengkerucutkan pilihan pada buku Coral Finder untuk mengetahui nama genus dari objek yang sedang kita amati sehingga karaketistik objek sesuai dengan yang ada di buku Coral Finder.

D. Setelah nama genus terumbu karang diketahui, tahapan selanjutnya adalah menentukan nama spesies dari objek tersebut. Dalam menentukan nama spesies karang, peneliti menggunakan buku panduan Coral of the world. Proses yang dilakukan dalam menentukan nama spesies karang tersebut harus dilakukan dengan teliti, dikarenakan bentuk koralit dan warna karang dapat menyerupai spesies karang lainnya. Dalam menentukan spesies terumbu karang yang ada di dalam buku Coral of the world, buku Coral Finder sudah memberikan panduan halaman yang akan dirujuk pada buku Coral of 
the world sehingga nama spesies yang akan diteliti vaild. Panduan rujukan halaman pada buku Coral Finder dan buku Coral of the World.

\section{Identifikasi Terumbu Karang}

Setelah melalui beberapa proses, mulai dari pengambilan sampel dilapangan hingga pembuatan gambar 3D dari sampel video. Maka dihasilkan bentuk gambar 3D, yang dapat dilihat pada gambar dibawah ini.

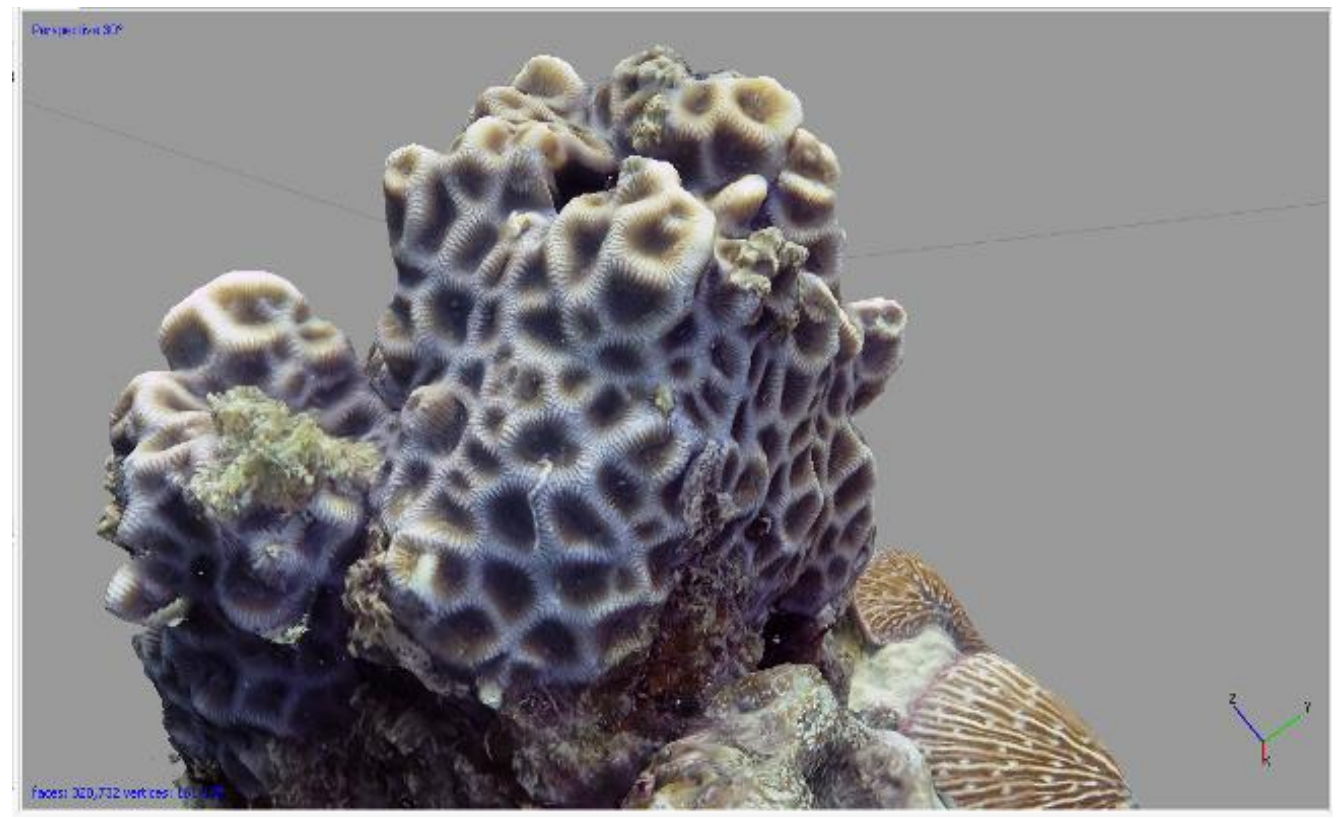

Gambar 2. Bentuk 3D Spesies Favites abdita

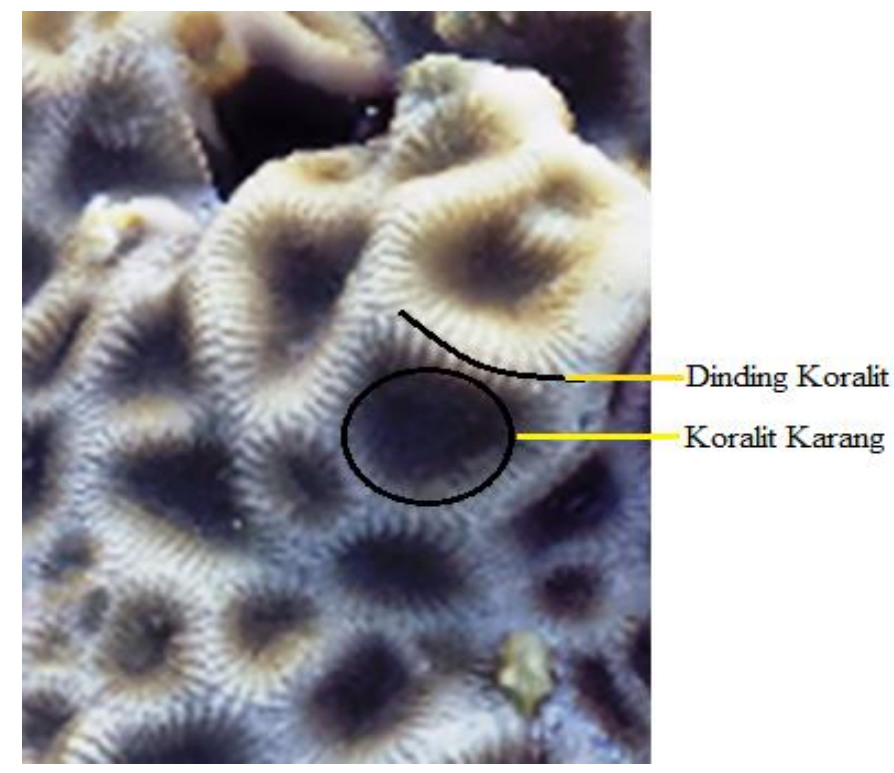

Gambar 3. Koralit Spesies Favites abdita 
Tabel 1. Hasil identifikasi karang Spesies Favites abdita

\begin{tabular}{lllll}
\hline Lifeform & Genus & Koralit & Warna & Spesies \\
\hline Massive & Favites & $\begin{array}{l}\text { 1. Ukuran koralit 10-14 mm } \\
\text { (0.39-0.55 inci) }\end{array}$ & Kekuningan & $\begin{array}{l}\text { Favites abdita, (Ellis and } \\
\text { Solander, 1786) }\end{array}$ \\
& & & \\
& $\begin{array}{l}\text { 2. Dinding koralit pada } \\
\text { karang menyatu (Shared }\end{array}$ & & \\
& & Walls). & Veron (2000). Coral Of The \\
& Kelley (2010). Coral & World, Vol.3, (hal:144) \\
& Finder, (hal: 15). & \\
\hline
\end{tabular}

Sumber : Data Primer (2018)

Hasil identifikasi yang telah dilakukan, sampel terkonfirmasi sebagai spesies sebagai berikut: Kingdom Animalia; Phylum Cnideria; Class Anthozoa; Ordo Scleractinia; Family Favidae; Genus Favites; dan Species F. abdita.

\section{KESIMPULAN}

Hasil penelitian ini menunjukan bahwa penggunaan metode RIKA-R3DI bisa dipergunakan secara efektif untuk mengidentifikasi spesies karang Genus Favites. Sama dengan penelitian sebelumnya, metode ini dapat membantu mengidentifikasi secara terkontrol bagi peneliti pemula. Sehingga metode ini dapat bermanfaat dan dikembangkan pada proses pembelajaran bagi seorang peneliti karang.

\section{REFERENSI}

Achmad, A., Munasik., Permata, D., 2013. Kondisi Ekosistem Terumbu Karang di Rote Timur, Kabupaten Rote Ndao, Taman Nasional Perairan Laut SAWU Menggunakan Metode Manta Tow. Journal of Marine Research, 2(3): 211-219.

Agisoft Photoscan LLC, 2014. Agisoft Photoscan User Manual. Rusia.

Fastawa., Fuad, Z., Hidayati, F., 2016. Komposisi Jenis dan Kepadatan Populasi Porifera di Kawasan Konservasi Sublitoral Rinon Pulo Breuh Kecamatan Pulo Aceh Kabupaten Aceh Besar. Prosiding Seminar Nasional Biotik. 34-36.

Giyanto., Abrar, M., Hadi, T.A., Budiyanto, A., Hafizt, M., Salatalohy, A., Iswari, M.Y. 2017. Status Terumbu Karang Indonesia 2017. Lembaga Ilmu Pengetahuan Indonesia Jakarta, Indonesia. 3. 
Giyanto., Manuputty, A.E.W., Abrar, M., Siringoringo, R.M., Suharti, S.R., Wibowo, K., Arbi, I.N.E.U.Y., Cappenberg, H.A.W., Sihaloho, H.F., 2014. Panduan Monitoring Kesehatan Terumbu Karang. Lembaga Ilmu Pengetahuan Indonesia Jakarta, Indonesia. Hal 9.

Hermanto, B., 2013. Keanekaragaman Karang Jamur (Fungiidae) di Perairan Pulau Siladen, Minahasa Utara. Jurnal Ilmiah Platax, 1(4): 158-166.

Hill, J., Wilkinson, C., 2004. Methods for Ecological Monitoring of Coral Reefs. Australian Institute of Marine Science, Townsvile. Version 1. 36p.

Ilyas, I.S., Astuty, S., Harahap, S.A., Purba, N.P., 2017. Keanekaragaman Ikan Karang Target Kaitannya dengan Keanekaragaman Bentuk Pertumbuhan Karang pada Zona Inti di Taman Wisata Perairan Kepulauan Anambas. Jurnal Perikanan dan Kelautan, 8(2): 103-111.

Kelley, R., 2010. Coral Finder, Byo Guides, Autralia, 29p

Kohler, K.E., Gill, S.M. 2006. Coral Point Count with Excel extensions (CPCe): A Visual Basic program for the determination of coral and substrate coverage using random point count methodology. National Coral Reef Institute. Nova Southeastern University Oceanographyc Centre. Dania Beach. USA. 32(1): 1259-1269.

Kurniawan, R., Yulianda, F., Susanto, H. A., 2016. Marine Tourism Sustainability Development in Marine Recreational Park Anambas Island. Jurnal Ilmu dan Teknologi Kelautan Tropis, 8(1): 367-383.

Kurniawan, R., Ariestasari, A., Silalahi, R. S., Karlin,I., Febrianto,T., Kurniawan, D., Amrifo, V., Abrar, M, Syakti, A.D., 2019. Identification Acroporidae and Favidae by a newly approach called Reef Identification Knowhow Application-Reconstructed by 3D Imagery (RIKA-R3DI) Method. MethodsX, 6:1084-1100.

Lasabuda, R., 2013. Pembangunan Wilayah Pesisir dan Lautan dalam Perspektif Negara Kepualauan Republik Indonesia. Jurnal Ilmiah Platax, 1(2): 92-101.

Lauretta, B., Reytar K., Spalding, M., Perry, A., 2012. Menengok Kembali Terumbu Karang yang Terancam di Segitiga Terumbu Karang. World Resources Institute. Hal 90.

Manuputty, A. E. W., Djuwariah, 2009. Point Intercept Transect (PIT) untuk Masyarakat. Studi Baseline dan Monitoring Kesehatan Karang di Lokasi Daerah Perlindungan Laut. Coremap II-LIPI, Jakarta. Hal 6

Mustamu, G., Lumingas, L.J., Lohoo, A.V., 2014. Kepadatan, Pola Sebaran, dan Morfometrik Kerak Kotak Septifer bilocularis (Linnaeus, 1758) pada Rataan Terumbu di Tanjung Lampangi, Minahasa Selatan. Jurnal Ilmiah Platax, 2(1): 8-18.

Prasetia, I.N.D., Wisnawa, I.G.D., 2015. Struktur Komunitas Terumbu Karang di Pesisir Kecamatan Buleleng Singaraja. Jurnal Sains dan Teknologi, 4(2): 579-590.

Restu, I.W., 2011. Kondisi Komunitas Terumbu Karang di Pantai Bias Putih Desa Bugbug Kecamatan Karangasem Kabupaten Karangaem Bali. Jurnal Bumi Lestari, 11(1): 5865 . 
Rudi, E., 2005. Kondisi Terumbu Karang di Perairan Sabang Nanggro Aceh Darussalam setelah Tsunami. Jurnal Ilmu Kelautan, 10(1): 50-60.

Saptarini, D., Mukhtasor., Rumengan, I.F.M., 2016. Variasi Bentuk Pertumbuhan (lifeform) Karang di Sekitar Kegiatan Pembangkit Listrik, Studi Kasus Kawasan Perairan PLTU Paiton Jawa Timur. Prosiding Semnas Biodiversitas. 41-49.

Sarbini, R., Kuslani, H., Nugraha, Y., 2016. Teknik Pengamatan Tutupan Terumbu Karang dengan Menggunakan Transek Garis (Line Intercept Transect) di Pulau Kumbang Kepulauan Karimun Jawa. Jurnal Balitbang, 14(1): 33-42.

Subhan, B., Rahmawati, F., Arafat, D., Bayu, N.A., 2011. Kondisi Kesehatan Karang Fungiidae di Perairan Pulau Pramuka, Kepulauan Seribu. Jurnal Teknologi Perikanan dan Kelautan, 2(1): 41-50.

Suharsono., 2008. Jenis-Jenis Karang di Indonesia. LIPI, Jakarta. Hal 375.

Sukmara, A., Siahainenia, A.J., Rotinsulu, C., 2001. Panduan Pemantauan Terumbu Karang Berbasis Masyarakat dengan Metode Manta Tow. Proyek Pesisir CRMP, Jakarta. Indonesia.

Sulistiana, I.N., Hidayat, B., Wardana, I.M.K., 2012. Identifikasi Terumbu Karang Berdasarkan Citra Penginderaan Jauh Multispektral dengan Filter 2D Gabor Wavelet dan K-nearest Neighbor (Skripsi). Telkom University.

Susanti, N., 2018. Upaya Greeanpeace Menjaga Kawasan Pantai Indonesia Terkait Proyek Pulau Reklamasi Teluk Jakarta di Universitas Riau. JOM FISIP, 4(2) : 1-18.

Tabugo, S. R. M., Manzanares, D. L., Malawani, A. D., 2016. Coral Reef Assessment and Monitoring Made Easy Using Coral Point Count with Excel Extensions (CPCe) Software in Calangahan, Lugait, Misamis Oriental, Philippines. Computational Ecology and Software of Journal, 6(1): 21-30.

Veron, 2000. Coral of The World. Australian Institute of Marine Science. University of Michigan, Vol. III, 1382p.

Thamrin., Siregar, Y.I., Zulkarnaini., Delpopi, M., 2013. Kondisi Terumbu Karang Pulau Kaisak Pariaman Provinsi Sumatera Barat Pasca Gempa Bumi Padang 30 September 2009. Jurnal Perikanan dan Kelautan, 18(1): 22-34. 